\title{
Health care workers' knowledge, attitudes and practices on tuberculosis infection control, Nepal
}

\author{
Anita Shrestha ${ }^{1 *}$, Dipesh Bhattarai ${ }^{2}$, Barsha Thapa ${ }^{3}$, Prem Basel $^{4}$ and Rajendra Raj Wagle ${ }^{4}$
}

\begin{abstract}
Background: Infection control remains a key challenge for Tuberculosis (TB) control program with an increased risk of TB transmission among health care workers (HCWs), especially in settings with inadequate TB infection control measures. Poor knowledge among HCWs and inadequate infection control practices may lead to the increased risk of nosocomial TB transmission.
\end{abstract}

Methods: An institution-based cross-sectional survey was conducted in 28 health facilities providing TB services in the Kathmandu Valley, Nepal. A total of $190 \mathrm{HCW}$ were assessed for the knowledge, attitudes and practices on TB infection control using a structured questionnaire.

Results: The level of knowledge on TB infection control among almost half (45.8\%) of the HCWs was poor, and was much poorer among administration and lower level staff. The knowledge level was significantly associated with educational status, and TB training and/or orientation received. The majority (73.2\%) of HCWs had positive attitude towards TB infection control. Sixty-five percent of HCWs were found to be concerned about being infected with TB. Use of respirators among the HCWs was limited and triage of TB suspects was also lacking.

Conclusions: Overall knowledge and practices of HCWs on TB infection control were not satisfactory. Effective infection control measures including regular skill-based training and/or orientation for all categories of HCWs can improve infection control practices in health facilities.

Keywords: Tuberculosis, Infection control, Health care workers, Knowledge, Attitudes and practices

\section{Background}

Tuberculosis (TB) remains a global public health threat affecting millions of people every year [1]. With the increasing incidence of drug resistance and HIV pandemic, TB control efforts have now become even more challenging and this has led to a greater concern towards TB infection control (IC). Institutional settings, including health care facilities, have been identified to be at high risk of TB transmission [2]. Studies have reported nosocomial transmission of TB with high TB infection among health care workers (HCWs) in many countries particularly in low- and middle-income countries [3-7]. This increased risk of TB transmission in health facilities put HCWs and other patients at high risk of infection

\footnotetext{
* Correspondence: anita.shrestha@uqconnect.edu.au

${ }^{1}$ University of Queensland, Brisbane, QLD, Australia

Full list of author information is available at the end of the article
}

leading to a serious threat particularly when concerned about drug-resistant (DR) and HIV associated TB [8].

Global experts recommend IC as one of the key strategies for TB control and there are TB IC guidelines available even for the resource-poor settings [9]. However, its implementation seems to be inadequate in many settings. Several studies have reported poor TB IC measures in health facilities [3,10-12]. Further, HCWs are practicing without adequate IC training and often lack knowledge on TB IC $[13,14]$. This is likely to contribute to the increased risk of nosocomial transmission of TB.

Like many other developing countries, TB is a priority public health problem in Nepal. There were an estimated 44,000 incident TB cases (156 per 100,000) and 6100 TB deaths in 2015 [1]. Drug resistance level is high with approximately $9.3 \%$ of new cases resistant to at least one drug. The rate of multi-drug resistant TB is 
$2.2 \%$ among new cases while it is $15.4 \%$ among retreatment cases [15]. Though HIV prevalence in the country is low, which is estimated at $0.2 \%$ among adult population [16], there have been reported high rates of TB/HIV coinfection [17-19]. The latest surveillance (2012) showed that HIV prevalence among TB cases is $2.4 \%$ while TB prevalence among HIV clients is $11.5 \%$. High levels of drug resistance and TB/HIV coinfection add more concerns towards IC, which remains a key challenge in Nepal [15]. National TB Programme (NTP) has not made significant effort to address the issue and no focal person has been assigned for IC at the national level. There does not exist any policy and/or guideline on TB IC to assist implementation of IC measures in health facilities. Information on TB IC knowledge and practices among HCWs can provide an important basis for NTP to initiate effort towards TB IC, but the relevant literature is lacking. Therefore, the study assessed knowledge, attitudes and practices (KAP) among HCWs on TB IC.

\section{Methods}

This study formed a part of a broader evaluation of TB infection among HCWs and IC infrastructure assessment in health facilities in three districts of Nepal. An institutionbased descriptive cross-sectional survey was carried out in Kathmandu, Lalitpur and Bhaktapur districts. There were 107 Directly Observed Treatment Short-course (DOTS) centres in the area. Due to logistic and time limitation, all health facilities could not be surveyed and therefore, health facilities were randomly selected from the list available from the National Tuberculosis Centre, Nepal. Since the study was a part of TB infection assessment among HCWs, the sample size was calculated based on the proportion of TB infection among HCWs. Due to the lack of information on the prevalence of latent TB infection among HCWs in Nepal, the prevalence was assumed to be $50 \%$ as informed by a study in India [20]. The confidence level and margin of error were $95 \%$ and 0.6 , respectively. All HCWs involved in TB services available during the study period were enrolled until the required sample number was met. Thus, a total of $190 \mathrm{HCWs}$ from 28 health facilities were surveyed. The health facilities included government (17) and nongovernment (11) facilities providing TB services in the area. Nine of them were hospitals and 19 were primary level health facilities. Since TB service in Nepal is integrated within the national health system and provided through the same outlet often within limited infrastructure, all HCWs are likely to be exposed to TB infection regardless of their job categories. Therefore, the study enrolled different cadres of HCWs who were directly or indirectly involved in TB care, which included physicians, nurses, community health care workers (CHWs) [health assistants, axillary health workers, axillary nurse midwives, and clinic assistants], laboratory and X-ray technicians, administration staff (administration and logistic staff, and TB volunteers), ward attendants and support staff.

A structured questionnaire was developed for data collection which included the specific components of TB IC questions relating to KAP and was based on tools used in similar studies $[12,13]$. The tool comprised of HCWs' demographic and service related variables (age, sex, education, job category, duration of employment, training/orientation on TB and TB IC); knowledge variables (general information on TB and IC measures); attitude variables (statements on TB and IC); and practice variables (time spent with $\mathrm{TB}$ suspects or patients, use of respirators, triage and patient education). The tool was translated into the Nepali language, pre-tested and revised as appropriate. Two field workers were trained on the final questionnaire and mobilised for the data collection. They visited the selected health facilities and conducted face-to-face interviews with the HCWs after obtaining informed consent. They were regularly monitored and supervised during the data collection process.

All completed questionnaires were cross-checked and edited on the same day and before data entry to ensure data consistency and completeness. All recorded data were coded and entered in Epi Data. Analyses were performed using Statistical Package for the Social Sciences (SPSS) for Windows software full version 18. Descriptive statistics and bivariate analyses were used for the analysis. HCWs' knowledge variables were scored and respondents answering $\geq 60 \%$ of the knowledge questions correctly were considered as having good level of knowledge and others were considered to have poor knowledge. The knowledge level was tested for the association with HCW' characteristics at significance level of 0.05 . The attitude variables comprised of 12 statements with response categories "Agree", "Disagree" or "Neutral". Composite scores were calculated and those scoring $\geq 70 \%$ were considered as having positive attitudes towards TB IC. The cut-off points for knowledge and attitude levels were set as informed by similar studies [21, 22].

\section{Results}

Of $190 \mathrm{HCWs}, 120(63.2 \%)$ were female and $70(36.8 \%)$ were male. The mean age of HCWs was $36 \pm 9.7$ (18-59) years. Table 1 shows that $42 \%$ of the HCWs were CHWs followed by administration staff (16.3\%), ward/support staff (16.3\%), nurses (10.5\%), lab/X-ray technician (10.5\%) and physician (4.2\%). Duration of employment of the HCWs ranged from less than 1 year $(8.4 \%)$ to 10 years and more (37.9\%). Nearly one-third of the HCWs (32.2\%) reported that they had received some level of training or orientation on TB and most of them were clinical staff (25.3\%) followed by lab/X-ray staff (5.3\%). Of those who reported receiving $\mathrm{TB}$ training 
Table 1 Sociodemographic characteristics of HCWs

\begin{tabular}{|c|c|c|c|}
\hline Variables & Categories & Frequency & Percentage \\
\hline \multirow[t]{3}{*}{ Age } & $18-30$ years & 63 & 33.2 \\
\hline & $31-40$ years & 69 & 36.3 \\
\hline & Above 40 years & 58 & 30.5 \\
\hline Mean + SD (range) & $36 \pm 9.7(18-59)$ & & \\
\hline \multirow[t]{2}{*}{ Sex } & Male & 70 & 36.8 \\
\hline & Female & 120 & 63.2 \\
\hline \multirow[t]{2}{*}{ Educational level } & Secondary and below & 130 & 68.4 \\
\hline & Tertiary and above & 60 & 31.6 \\
\hline \multirow[t]{6}{*}{ Job category } & Physician & 8 & 4.2 \\
\hline & Nurse & 20 & 10.5 \\
\hline & CHWs & 80 & 42.1 \\
\hline & Lab/X-ray technician & 20 & 10.5 \\
\hline & $\begin{array}{l}\text { Ward attendant/ } \\
\text { support staff }\end{array}$ & 31 & 16.3 \\
\hline & Administrative staff & 31 & 16.3 \\
\hline \multirow{4}{*}{$\begin{array}{l}\text { Duration of } \\
\text { employment }\end{array}$} & Less than 1 year & 16 & 8.4 \\
\hline & $1-4$ years & 54 & 28.4 \\
\hline & $5-9$ years & 48 & 25.3 \\
\hline & 10 years and above & 72 & 37.9 \\
\hline \multirow{4}{*}{$\begin{array}{l}\text { Training or orientation } \\
\text { on TB }\end{array}$} & Clinical staff & 48 & 25.3 \\
\hline & Lab/x-ray staff & 10 & 5.3 \\
\hline & $\begin{array}{l}\text { Ward attendant/ } \\
\text { support staff }\end{array}$ & 1 & 0.5 \\
\hline & Administrative staff & 2 & 1.1 \\
\hline $\begin{array}{l}\text { Training or orientation } \\
\text { on TB IC }\end{array}$ & Yes & 7 & 11.5 \\
\hline$(n=61)$ & No & 54 & 88.5 \\
\hline
\end{tabular}

and/or orientation, only $12 \%$ had received TB IC specific training.

\section{Knowledge of HCWs on TB IC}

Table 2 shows knowledge of HCWs on TB IC. Most of the HCWs were aware of the major symptoms (67.4\%) and route of TB transmission (81.6\%). However, only half of them $(54.7 \%)$ could differentiate between TB infection and TB disease. Nine out of ten HCWs stated that use of respirators can prevent TB infection and regarding the IC measures to be implemented in health facilities, $55 \%$ of them stated personal respiratory protection followed by environmental controls (47.4\%) and administrative controls (14.7\%).

Mean score of knowledge on TB IC among HCWs was $10.56 \pm 4.29$. The result shows that $54 \%$ of $\mathrm{HCWs}$ scored "good" level of knowledge while $46 \%$ of them had "poor" knowledge level. Table 3 shows that knowledge level of the HCWs was significantly associated with educational status, job category and $\mathrm{TB}$ training or orientation received by the HCWs.

\section{Attitude of HCWs towards TB IC}

Our study found that the majority (73.2\%) of HCWs had positive attitudes towards TB IC. As shown in Table 4, almost all HCWs agreed that there is a need for a TB IC guideline in health facilities (99.5\%). Almost all of them $(98.4 \%)$ agreed that they should wear respirators while caring for TB patients. Majority of HCWs (64.7\%) were concerned about being infected with TB and nearly one fifth of them agreed that cough hygiene alone has no role in TB IC. The analysis shows that HCWs' attitude level was significantly associated with their level of knowledge on TB IC.

\section{Practice of HCWs on TB IC}

Table 5 shows that $48 \%$ of the HCWs were exposed to TB patients up to $25 \%$ of their working day and one-fourth of them usually spent 25 to $50 \%$ of their time with TB patients. Thirty-eight percent of them never used respirators and only $10 \%$ of them reported using N-95 mask. While enquiring about their practice after seeing a coughing patient in the health facility, most of them (59.5\%) replied that they ask the patient to cover his/her mouth while one-fourth (25.3\%) of them stated that they do nothing. For patient education, only medical staff were considered as administration and support staff were not supposed to provide health education. Of them, $38 \%$ stated that they inform TB patients or suspects of cough etiquette and respiratory hygiene on daily basis.

\section{Discussion}

The KAP assessment showed that overall knowledge and practices of HCWs on TB IC were not satisfactory. TB was well understood among HCWs as the majority of them were aware of signs and symptoms of TB, and its transmission. However, TB IC specific knowledge level was poor. Most often HCWs lack proper knowledge in TB IC despite having the good level of understanding on general information regarding TB $[13,23]$. The percentage of HCWs scoring "good" knowledge level was 54, relatively less than reported $74 \%$ in Ethiopia [21]. The variation in the percentage can be attributed to different methodological approaches where HCWs in the Ethiopian study represented clinical personnel while our study also included administration and other staff.

On contrary to other similar studies [22, 24, 25], we assessed all cadres of HCWs due to their probable exposure to TB infection and having an important role in implementing IC measures in health facilities. Prevention of nosocomial TB transmission requires that all HCWs are aware of TB IC and ensure adequate practices in health facilities. Most often non-medical staff are 
Table 2 Knowledge of HCWs on TB IC

\begin{tabular}{|c|c|c|c|c|c|}
\hline \multirow[t]{2}{*}{ Knowledge questions on TB IC } & \multicolumn{5}{|c|}{ Correct response (\%) } \\
\hline & $\begin{array}{l}\text { All HCWs } \\
(n=190)\end{array}$ & $\begin{array}{l}\text { Clinical staff } \\
(n=108)\end{array}$ & $\begin{array}{l}\text { X-ray/ Lab staff } \\
(n=20)\end{array}$ & $\begin{array}{l}\text { Admin. staff } \\
(n=31)\end{array}$ & $\begin{array}{l}\text { Ward/ support } \\
\text { staff }(n=31)\end{array}$ \\
\hline \multicolumn{6}{|l|}{ What are symptoms of TB? } \\
\hline Cough for 2 weeks or more & $128(67.4)$ & $82(75.2)$ & $12(63.2)$ & $11(35.5)$ & $23(74.2)$ \\
\hline Weight loss & $143(75.3)$ & $96(88.1)$ & $14(73.7)$ & $13(41.9)$ & $20(64.5)$ \\
\hline Fever & $162(85.3)$ & $101(92.7)$ & $18(94.7)$ & $19(61.3)$ & $24(77.4)$ \\
\hline Loss of appetite & $110(57.9)$ & $69(63.3)$ & $16(52.6)$ & $10(32.3)$ & $13(41.9)$ \\
\hline Chest pain & $129(67.2)$ & $89(81.7)$ & $15(78.9)$ & $9(29.0)$ & $16(51.6)$ \\
\hline Blood in sputum & $117(61.6)$ & $75(68.8)$ & $13(68.4)$ & $11(35.5)$ & $18(58.1)$ \\
\hline How is TB transmitted? & $155(81.6)$ & $101(92.7)$ & $16(84.2)$ & $15(48.4)$ & $23(74.2)$ \\
\hline What is difference between TB infection and disease? & $104(54.7)$ & $74(67.9)$ & $13(68.4)$ & $4(12.9)$ & $13(41.9)$ \\
\hline Definition of TB suspects & $101(53.2)$ & $66(60.6)$ & $13(68.4)$ & $6(19.4)$ & $16(51.6)$ \\
\hline Which TB is infectious? & $155(81.6)$ & $105(96.3)$ & $18(94.7)$ & $12(38.7)$ & $20(64.5)$ \\
\hline How long is a TB patient infectious after starting treatment? & $60(31.6)$ & $46(42.2)$ & $5(26.3)$ & $3(9.7)$ & $6(19.4)$ \\
\hline \multicolumn{6}{|l|}{ In what ways, can HCWs prevent TB infection? } \\
\hline Use of respirators by HCWs & $175(92.1)$ & $104(95.4)$ & $16(84.2)$ & $27(87.1)$ & $28(90.3)$ \\
\hline Use of masks by patients & $65(34.2)$ & $42(38.5)$ & $9(47.4)$ & $3(9.7)$ & $11(35.5)$ \\
\hline \multicolumn{6}{|l|}{ What are IC measures in health facilities? } \\
\hline Administrative controls & $28(14.7)$ & $16(14.7)$ & $8(42.1)$ & $0(0.0)$ & $4(12.9)$ \\
\hline Environmental controls & $90(47.4)$ & $61(56)$ & $10(52.6)$ & $5(16.1)$ & $14(45.2)$ \\
\hline Personal respiratory protection & $105(55.3)$ & $62(56.9)$ & $17(89.5)$ & $10(32.3)$ & $16(51.6)$ \\
\hline
\end{tabular}

Table 3 HCWs characteristics and knowledge level on TB IC

\begin{tabular}{|c|c|c|c|c|}
\hline \multirow[t]{2}{*}{ HCWs' characteristics } & & \multicolumn{2}{|c|}{ Knowledge level } & \multirow{2}{*}{$\begin{array}{l}P \\
\text { value }\end{array}$} \\
\hline & & Good & Poor & \\
\hline \multirow[t]{3}{*}{ Age } & $18-30$ years & $37(35.9)$ & $26(29.9)$ & \\
\hline & $31-40$ years & 39 (37.9) & $30(34.5)$ & 0.361 \\
\hline & Above 40 years & $27(26.2)$ & $31(35.6)$ & \\
\hline \multirow[t]{2}{*}{ Sex } & Male & $41(39.8)$ & $29(33.3)$ & \\
\hline & Female & $62(60.2)$ & $58(66.7)$ & 0.357 \\
\hline \multirow[t]{2}{*}{ Educational level } & Secondary and below & $59(57.3)$ & $71(81.6)$ & $0.000^{*}$ \\
\hline & Tertiary and above & $44(42.7)$ & $16(18.4)$ & \\
\hline \multirow[t]{4}{*}{ Job category } & Clinical staff & $72(69.9)$ & $37(45.5)$ & \\
\hline & Lab/X-ray staff & $13(12.6)$ & $6(6.9)$ & $0.000^{*}$ \\
\hline & Administrative staff & $13(12.6)$ & $18(20.7)$ & \\
\hline & Ward/support staff & $5(4.8)$ & $26(29.9)$ & \\
\hline \multirow[t]{3}{*}{ Duration of employment } & Less than 5 years & 39 (37.9) & $31(35.6)$ & \\
\hline & $5-9$ years & $25(24.3)$ & $23(26.4)$ & 0.927 \\
\hline & 10 years and above & 39 (37.9) & $33(37.9)$ & \\
\hline \multirow[t]{2}{*}{ Training or orientation on TB } & Yes & $49(47.6)$ & $12(13.8)$ & \\
\hline & No & $54(52.4)$ & $75(86.2)$ & $0.000^{*}$ \\
\hline
\end{tabular}


Table 4 Attitudes of HCWs towards TB IC

\begin{tabular}{|c|c|c|c|}
\hline Statement & Agree & Neutral & Disagree \\
\hline There is a need for guidelines regarding TB IC in a health care facility & $189(99.5)$ & $1(0.5)$ & $0(0.0)$ \\
\hline HCWs should wear respirators while caring for TB patients & $187(98.4)$ & $1(0.5)$ & $2(1.1)$ \\
\hline Respirators do not protect against drug-resistant TB even if I wear it all time & $95(50)$ & $7(3.7)$ & $88(46.3)$ \\
\hline Even after a patient with TB leaves the room I am working in, I remain at risk of contracting TB & $163(85.8)$ & $3(1.6)$ & $24(12.6)$ \\
\hline Most HCWs are already infected so there is no need of IC measures & $12(6.3)$ & $2(1.1)$ & $176(92.6)$ \\
\hline I do not wear respirator because patients do not like me to wear it & $32(16.8)$ & $0(0.0)$ & $158(83.2)$ \\
\hline I am concerned about being infected with TB & $123(64.7)$ & $0(0.0)$ & $67(35.3)$ \\
\hline There is need to screen HCWs who may be exposed to TB for TB infection or disease & $189(99.5)$ & $0(0.0)$ & $1(0.5)$ \\
\hline I may turn off fans if they become noisy or cause cold air & $155(81.6)$ & $2(1.1)$ & $33(17.4)$ \\
\hline Sputum induction procedures in wards put HCWs at an increased risk of getting infected with TB & $175(92.1)$ & $2(1.1)$ & $13(6.8)$ \\
\hline Cough hygiene has no role to play in IC & $36(18.9)$ & $2(1.1)$ & $152(80)$ \\
\hline HCWs working in HIV care and treatment clinics are at risk of infection with TB & $154(81.1)$ & $2(1.1)$ & $34(17.9)$ \\
\hline
\end{tabular}

Table 5 Practices of HCWs on TB IC

\begin{tabular}{lcc}
\hline IC practice & Frequency & Percentage \\
\hline Proportion of shift spent with TB patients & & \\
Less than 25\% & 91 & 47.9 \\
$26-50 \%$ & 47 & 24.7 \\
$51-75 \%$ & 38 & 20.0 \\
Above 75\% & 14 & 7.4 \\
Proportion of shift worn respirator & & \\
Not at all & 73 & 38.4 \\
Less than 25\% & 79 & 41.6 \\
26-50\% & 18 & 9.5 \\
51-75\% & 6 & 3.1 \\
Above 75\% & 14 & 7.4 \\
Type of respirator used & & \\
N-95 mask & 19 & 10.0 \\
Surgical mask & 68 & 35.8 \\
Ordinary mask & 30 & 15.8 \\
What did they do for coughing patient in queue & \\
Ask duration of their cough & 56 & 29.5 \\
Place them in separate waiting area & 6 & 3.2 \\
Place them in front of queue & 6 & 3.2 \\
Inform about cough etiquette & 113 & 5.3 \\
Do nothing & 48 & 14.1 \\
Patient education on cough etiquette (medical staff only, & & \\
Always & 49 & $128)$ \\
Sometimes & 55 & 3.3 \\
Never & 6 & \\
As per the need & & \\
\hline
\end{tabular}

ignored in training, respirator use, etc. while their risk of being infected and implications in IC interventions cannot be undermined. Not surprisingly, the study revealed significant differences in knowledge level among different categories of HCWs. The knowledge level was relatively good among medical staff compared to administration staff and was much lower among ward/ support staff. The higher knowledge level among the medical staff is obvious because they have TB and IC components covered during their study and are also likely to have received relevant training.

Our study has clearly indicated a gap in training and/or orientation on TB IC for HCWs which could have attributed to poor knowledge level particularly among administration and lower qualified staff. NTP Nepal provides regular basic and refresher trainings for various categories of HCWs. However, much of these trainings focus on clinical management of $\mathrm{TB}$ and such trainings rarely include non-medical personnel. Furthermore, TB IC specific training or orientation package is lacking, focusing the need of regular training for all HCWs. It is also important to consider how effective are the trainings to bring about desired changes in IC practices. Proper knowledge has been identified to be a predictor of good IC practice and notwithstanding that TB related training is associated with good knowledge, it does not necessarily ensure adequate IC practices [21, 24, 25]. Rather than conventional training, skill-based training utilizing adult learning approaches aimed at modifying HCWs' behaviour can improve IC practices in the health facilities.

Effective implementation of IC measures in health facilities also relies on HCWs' appropriate attitudes and motivation. Despite having appropriate attitude towards TB IC, HCWs' fear for contracting TB is noteworthy. This fear could often be relating to infecting others including family members and the possible financial implications associated after being infected [14, 26]. The 
study also highlighted HCWs' realization for the need of regular screening along with the use of respirators while caring for TB patients. However, the use of respirators was very limited. There is no regular supply of respirators especially the N-95 masks for HCWs, which was supported by our observation during IC infrastructure assessment and this probably could be a reason for the limited use. A study [27] has also pointed unavailability of respirators as a barrier to respirators use. Similarly, stigma associated with TB could also be one of the reasons as HCWs reported of avoiding respirators for the comfort of patients. The study also revealed the inadequate practice of triage and poor patient education. Unlike a South African study [13], we noted very low percentage of HCWs providing information on cough etiquette to their patients on daily basis, reflecting the need to focus more on patient education.

The knowledge deficit and inadequate IC practices of HCWs are major barriers to implement IC measures resulting in an increased risk of TB transmission in health facilities. The poor knowledge and practices could be attributed to lack of TB IC policy and/or guideline both at national and institutional levels. NTP Nepal has not yet adapted or formulated the country specific TB IC guideline. Thus, health facilities are not obliged to strictly implement the recommended IC measures and HCWs are not familiar with the IC standards. It is imperative that NTP seriously pay attention towards the issue and this study can provide a sound evidence base to initiate development of TB IC guideline. Given limited resources, NTP may not be able to immediately afford expensive structural and environmental adjustments. As such, cost-effective and sustainable approaches can be taken into consideration. For instance, simply making HCWs aware of necessary IC measures like triage, proper sputum handling, respiratory hygiene and patient education can significantly minimise the risk of TB transmission in the health care settings.

There are certain limitations in our study. The study was conducted in a small population limiting the generalizability of the findings. TB IC practices in the study are self-reported based on the anonymous questionnaires rather than observation. Nevertheless, this is a first attempt to study HCWs' KAP regarding TB IC in Nepal. The findings can serve as a baseline to design effective interventions to address the challenging issue of IC in relation to the possible threat of drug resistance and TB/HIV coinfection in the country. Further study at large scale preferably relying on observation of the IC practices is recommended.

\section{Conclusions}

Overall knowledge and practices of HCWs on TB IC were not satisfactory with the knowledge level being even worse among non-medical and lower level staff. Regular skillbased training and orientation on TB IC for all cadres of
HCWs can improve IC practices in the health facilities. In addition, TB IC policy or guideline is recommended to ensure effective IC measures in health facilities.

\section{Abbreviations}

CHWs: Community health workers; DOTS: Directly observed treatment shortcourse; DR TB: Drug-resistant tuberculosis; HCW: Health care worker; HIV: Human immunodeficiency virus; IC: Infection control; KAP: Knowledge attitudes and practices; NTP: National Tuberculosis Program; SD: Standard deviation; SPSS: Statistical package for social sciences; TB: Tuberculosis

\section{Acknowledgements}

We would like to acknowledge National TB center, Bhaktapur, Nepal, District Public Health Offices, and health facilities of Kathmandu, Bhaktapur and Lalitpur districts, and all the health care workers for their cooperation and participation in the study.

\section{Funding}

The study did not receive any funding.

Availability of data and materials

All data generated or analysed during this study are included in the article.

Authors' contributions

AS designed the study. AS, DB and BT conducted the study and were responsible for data analysis. AS and DB wrote the manuscript. RW and PB supervised the overall research process providing valuable inputs and guidance since the study design through manuscript writing. All authors provided input to and approved the final manuscript.

Ethics approval and consent to participate

The study received approval from Institution Review Board of Institute of Medicine, Tribhuvan University, Nepal. All interviews were conducted with the participants' written informed consent. Each participant in the study was clearly explained of the study objectives, informed of their rights to deny participation and assured for the confidentiality of the information provided.

Consent for publication

Not applicable.

\section{Competing interests}

The authors declare that they have no competing interests.

\section{Publisher's Note}

Springer Nature remains neutral with regard to jurisdictional claims in published maps and institutional affiliations.

\section{Author details}

'University of Queensland, Brisbane, QLD, Australia. ${ }^{2}$ Queensland University of Technology, Brisbane, QLD, Australia. ${ }^{3}$ Save the Children in Nepal/Regional TB Center, Kaski, Pokhara, Nepal. ${ }^{4}$ Department of Community Medicine and

Public Health, Institute of Medicine, Tribhuvan University, Kathmandu, Nepal.

Received: 3 February 2017 Accepted: 12 November 2017

Published online: 17 November 2017

\section{References}

1. World Health Organization. Global Tuberculosis Report 2016. Geneva: WHO; 2016.

2. World Health Organization. WHO policy on TB infection control in healthcare facilities, congregate settings and households. Geneva: WHO; 2009.

3. He GX, van den Hof S, van der Werf MJ, Wang GJ, Ma SW, Zhao DY, et al. Infection control and the burden of tuberculosis infection and disease in health care workers in china: a cross-sectional study. BMC Infect Dis. 2010;10:313.

4. Joshi R, Reingold AL, Menzies D, Pai M. Tuberculosis among health-care workers in low- and middle-income countries: a systematic review. PLoS Med. 2006;3(12):2376-91.

5. Schablon A, Harling M, Diel R, Nienhaus A. Risk of latent TB infection in individuals employed in the healthcare sector in Germany: a multicentre prevalence study. BMC Infect Dis. 2010;10:107. 
6. Gandhi NR, Weissman D, Moodley P, Ramathal M, Elson I, Kreiswirth BN, et al. Nosocomial transmission of extensively drug-resistant tuberculosis in a rural hospital in South Africa. J Infect Dis. 2013;207(1):9-17.

7. Menzies D, Joshi R, Pai M. Risk of tuberculosis infection and disease associated with work in health care settings [state of the art series. Occupational lung disease in high- and low-income countries]. Int J Tuberc Lung Dis. 2007;11(6):593-605.

8. World Health Organization. Guidelines for the programmatic management of drug-resistant tuberculosis emergency update 2008. Geneva: World Health Organization; 2008.

9. Granich R, Binkin NJ, Jarvis WR, Simone PM, Rieder HL, Espinal MA, et al. Guidelines for the prevention of tuberculosis in health care facilities in resource-limited settings. Geneva: World Health Organization; 1999.

10. Ogbonnaya LU, Chukwu JN, Uwakwe KA, Oyibo PG, Ndukwe CD. The status of tuberculosis infection control measures in health care facilities rendering joint TB/HIV services in "German leprosy and tuberculosis relief association" supported states in Nigeria. Niger J Clin Pract. 2011;14(3):270-5.

11. Sissolak D, Marais F, Mehtar S. TB infection prevention and control experiences of south African nurses-a phenomenological study. BMC Public Health. 2011;11:262.

12. Farley JE, Tudor C, Mphahlele M, Franz K, Perrin NA, Dorman S, et al. A national infection control evaluation of drug-resistant tuberculosis hospitals in South Africa. Int J Tuberc Lung Dis. 2012;16(1):82-9.

13. Kanjee Z, Catterick K, Moll AP, Amico KR, Friedland GH. Tuberculosis infection control in rural South Africa: survey of knowledge, attitude and practice in hospital staff. J Hosp Infect. 2011;79(4):333-8.

14. Woith W, Volchenkov G, Larson J. Barriers and motivators affecting tuberculosis infection control practices of Russian health care workers. Int J Tuberc Lung Dis. 2012;16(8):1092-6.

15. National Tuberculosis Centre, Ministry of Health and Population Government of Nepal. National Tuberculosis Programme Annual Report 2015. Bhaktapur: NTC; 2016.

16. National Centre for AIDS and STD Control, Ministry of Health and Population, Government of Nepal. Country Progress Report Nepal 2015. Kathmandu: NCASC; 2015.

17. Dhungana GP, Sharma S, Khadga P, Verma SC. Surveillance of tuberculosis among HIV infected persons in three different regions of Nepal. Nepal Med Coll J. 2013;15(2):113-6.

18. Verma SC, Dhungana GP, Joshi HS, Kunwar HB, Pokhrel AK. Prevalence of pulmonary tuberculosis among HIV infected persons in Pokhara, Nepal. J Nepal Health Res Counc. 2012;10(1):32-6.

19. Tiwari BR, Karki S, Ghimire P, Sharma B, Malla S. Factors associated with high prevalence of pulmonary tuberculosis in HIV-infected people visiting for assessment of eligibility for highly active antiretroviral therapy in Kathmandu, Nepal. WHO South East Asia J Public Health. 2012;1 (4):404-11.

20. Pai M, Gokhale K, Joshi R, Dogra S, Kalantri S, Mendiratta DK, et al. Mycobacterium tuberculosis infection in health care workers in rural India: comparison of a whole-blood interferon gamma assay with tuberculin skin testing. JAMA. 2005;293(22):2746-55.

21. Temesgen C, Demissie M. Knowledge and practice of tuberculosis infection control among health professionals in Northwest Ethiopia; 2011. BMC Health Serv Res. 2014;14(1):593.

22. Bhebhe LT, Van Rooyen C, Steinberg WJ. Attitudes, knowledge and practices of healthcare workers regarding occupational exposure of pulmonary tuberculosis. Afr J Prm Healthcare Fam Med. 2014;6(1):E1-6.

23. Woith WM, Volchenkov G, Larson JL. Russian health care workers' knowledge of tuberculosis and infection control. Int J Tuberc Lung Dis. 2010;14(11):1489-92.

24. Demissie Gizaw G, Aderaw Alemu Z, Kibret KT. Assessment of knowledge and practice of health workers towards tuberculosis infection control and associated factors in public health facilities of Addis Ababa, Ethiopia: a cross-sectional study. Arch Public Health. 2015;73(1):15.

25. Engelbrecht M, Janse van Rensburg A, Kigozi G, van Rensburg HD. Factors associated with good TB infection control practices among primary healthcare workers in the free State Province, South Africa. BMC Infect Dis. 2016;16(1):633.

26. Tudor C, Mphahlele M, Van der Walt M, Farley JE. Health care workers' fears associated with working in multidrug- and or extensively-resistant tuberculosis wards in South Africa. Int J Tuberc Lung Dis. 2013;17(10 Suppl 1):22-9.

27. Mirtskhulava V, Whitaker JA, Kipiani M, Harris DA, Tabagari N, Owen-Smith AA, et al. Determinants of tuberculosis infection control-related behaviors among healthcare workers in the country of Georgia. Infect Control Hosp Epidemiol. 2015;36(5):522-8.

\section{Submit your next manuscript to BioMed Central and we will help you at every step:}

- We accept pre-submission inquiries

- Our selector tool helps you to find the most relevant journal

- We provide round the clock customer support

- Convenient online submission

- Thorough peer review

- Inclusion in PubMed and all major indexing services

- Maximum visibility for your research

Submit your manuscript at www.biomedcentral.com/submit 